\title{
Implementing K-Means Clustering Algorithm in Collaborative Trip Advisory and Planning System
}

\author{
Lim Yen Yee ${ }^{1}$, Seetha Letchumy M Belaidan ${ }^{1}$, Nor Azlina Abd Rahman ${ }^{1}$, Khalida \\ Shajaratuddur Harun ${ }^{1}$ \\ ${ }^{1}$ Asia Pacific University of Technology \& Innovation \\ Technology Park Malaysia, 57000 Bukit Jalil, Kuala Lumpur
}

\section{Article Info}

Received Feb 2, 2019

\section{Keyword:}

Trip Advisory

Trip Planning

K-Means Algorithm

\begin{abstract}
Fueled by the help of the Internet, more and more tourists nowadays tend to plan trips by themselves in order to have trip plans that meet their preferences and convenience perfectly. However, tourists may face some problems when they plan a trip by themselves, which makes the whole trip planning process challenging and tiring. These problems include extensive tourism information, manually constructing an itinerary for a trip and difficulty in satisfying the needs of all trip participants. Therefore, a web-based trip planning system is proposed in this project to solve all these problems in order to help tourists in planning their desired trips more effectively and efficiently. This system will help users to search for attractions and restaurants in Southeast Asian countries faster by providing filtering and prioritizing features. This system also facilitates the decision-making process of tourists when choosing places to visit and restaurants by utilizing the power of word-of-mouth (reviews). Besides, this system will aid tourists by reducing the need to manually construct the itinerary for a trip. The k-means clustering algorithm will be used to auto-arrange the trip itinerary to ensure places close to each other are arranged to be visited on the same day so that tourists can save on unnecessary transport costs and time. Lastly, this system promotes collaborative trip planning by providing a platform for all the participants in a trip to discuss and plan their trip together.
\end{abstract}

\section{Corresponding Author:}

Seetha Letchumy M. Belaidan,

Asia Pacific University of Technology \& Innovation,

Technology Park Malaysia,

57000 Bukit Jalil, Kuala Lumpur

Email: seetha@apu.edu.my

\section{Introduction}

The tourism sector has a great influence in the growth and income of countries in Southeast Asia. According to UNWTO and GTERC [1], Asia and the Pacific region earned a whopping USD418 billion in tourism receipts in 2015 and Southeast Asia being one of the sub-regions accounted for $26 \%$ of those total tourism receipts. In the year 2016, the total international tourist arrivals in Southeast Asia has increased about $8 \%$ and 
reached a total of 113.3 million arrivals [1]. This shows that more and more people like travelling and many countries in Southeast Asia have benefited from the growth in tourism.

Internet has granted users access to a vast pool of information. Due to this, more and more tourists prefer to plan their trips themselves using the information available online to save on the commission paid to travel agents and have more flexibility in choosing places to visit and restaurants at a destination. However, tourists may face some problems while planning their trips by themselves.

Januszewska, Jaremen and Nawrocka [2] claimed that tourism is an information-intensive industry. Although there are many online or printed resources which provide information for people to plan their trips, trip planning is still a time-consuming and tiring task as these resources are overloaded with extensive information which may be irrelevant and may provide too many options without taking their needs and preferences into account. Moreno, Sebastia \& Vansteenwegen [3] mentioned that the huge amount of online tourism information has made trip preparation very challenging. While dealing with extensive information, it is time consuming for people to find out the relevant information for deciding the places to visit and restaurants for a trip. Luz et al. [4] stated that another problem of this huge amount of information is that trip participants are unaware of each other's presence and do not give complete information about the places they describe. Tourists would have to search through multiple resources in order to gather the right amount of information they need.

Tourists hesitate about the places they "should go" and "should not be missed out" at a destination if too many options are provided. The study done by Park and Jang [5] has mentioned that "choice overload" happens in tourism and having more than 22 options will probably cause people to make no choices at all or experience regret. Tourists regret if they had chosen places which they found unworthy of visiting later on in the trip.

After finding out the right places to go, tourists also have to spend time on planning the itinerary of the trip. Tourists are unable to visit every single tourist spot in their travel destination due to time constraints. However, it is also difficult for tourists to come up with an optimal itinerary when they plan to visit unfamiliar places [6]. Lim [7] also mentioned that creating an itinerary of sequential attractions and restaurants is a tedious task as there are many considerations to be made when planning the itinerary such as time availability and starting/ending points. Besides, the information gathering process and itinerary constructing process includes much tedious manual work. Tourists may first search for places they would like to visit and record these places manually. After that, tourists may construct the itinerary on a spreadsheet or a document and input the gathered information into the itinerary manually, which is a time-consuming process. After the itinerary is ready, the tourist has to also share it with other participants of the trip and answer their queries.

Lastly, organising a trip which best satisfies all participants is a challenge when planning a trip. Dareddy [8] mentioned that people normally travel in groups but existing travel recommendation systems focus on meeting the preference of a single person rather than all the participants in a trip. Lim [7] also mentioned that it is challenging for travel agencies to group tourists into a group as the suggested tour may not meet the preferences of all group members. The reason is that people traveling in a group may have different or even conflicting preferences on the type of attractions and restaurants they wish to visit in a trip. Another reason that makes group trip planning difficult is the lack of communication between the trip organiser and the participants in the trip. Sometimes, the trip organiser does not know the preferences of other participants in the trip even though the organiser wants to satisfy them. On the other hand, participants in a trip may not know what has been planned and decided by the trip organiser until the organiser is finished with the planning and shares the results with them. In other words, other participants in a trip are unable to be actively involved in the trip planning and give their suggestions.

\section{Review on Existing System}

In this section, three similar systems which share similar features with the proposed system are studied and compared to determine their benefits and limitations in trip planning. The research result is used to improve the proposed system. 


\subsection{TripAdvisor}

TripAdvisor is the world's largest travel site founded in 2000 with an average of 415 million monthly unique visitors and more than 500 million reviews for over 7 million airlines, accommodations, attractions and restaurants worldwide [9]. TripAdvisor is well-known as the largest travel review site and is a powerful tool for helping travelers to decide where to stay, where to visit, where to eat and how to fly by providing the opinions and past experiences of peer travelers.

The benefit of using TripAdvisor for trip planning is that it utilizes word of mouth (reviews) to facilitate the decision making process. It combines all the necessary elements that comprise a trip, which are flights, accommodation, restaurants and attractions. Travelers can search for the information and reviews of all these elements in TripAdvisor without having to visit multiple websites to gather the needed information. Another good thing is that TripAdvisor partnered with many airlines, travel agents and booking agents to provide booking services. Travelers can book for flights, tours and accommodations. To make the searching easier, TripAdvisor utilizes different recommendation approaches in different aspects. For example, when users search and view a hotel, similar hotels will be recommended for comparison purposes (content-based recommendation). If the users search for restaurants or attractions, nearby restaurants and attractions will be recommended (location-based recommendation). Besides, when users search for hotels, restaurants and attractions, they can filter the options based on their needs and preferences and prioritize the results according to the ranking of the places. As mentioned by Luz et al. [4], registered users of TripAdvisor will have trip folders which store the notes, links and places to visit for all their trips. This will let users to keep track and manage all their trips easier. Luz et.al [4] also mentioned that registered users can also create a map which marks the places they would like to visit.

The limitation of TripAdvisor is that it is for satisfying the needs and preferences of a single user when making recommendations of places to stay, visit and eat. However, people normally travel in groups. Besides, although there are many features provided by TripAdvisor, but this also make the display of contents look rather messy. The filtering process includes many steps as there are many filtering criteria that are very specific. For example, a user first chooses sights \& landmarks as type of attraction, the user then chooses the type of sights \& landmarks he/she wants to visit. For people who cannot specify clearly their preference, they may feel confused.

\subsection{TripHobo}

TripHobo is a platform which does trip planning that help users to draft trips on places, restaurants and package tours from over 90,000 cities around the world. It is an online application where it functions as a onestop center for all the travel requirements covering places of interest, planning itineraries, package tours and ground arrangement such as accommodations and local transportation. If the places are not available on the current list, users can add a place directly from Google as shown in Figure 1 and Figure 2. Users are able to customize their itineraries by registering as members. Alternatively, users could share their travel plans with others by registering via Facebook accounts. Itineraries are shareable on Google+ and Twitter platforms as well [10].

The interface is user friendly with drag and drop features, adding trips to the selected days, and adding days and route optimization. Although the route optimization would be able to provide notification that the itineraries are almost full for the day and user could not add more, it does not have any function to group nearby places into the same day of visit as shown in Figure 3. TripHobo is able to estimate the distance and travel time from one location to the other, as well as indicate the opening and closing times for each place. However, the planning does estimate the time spent by the users at each place. The estimated time is however a minimum time to the tourist, of which some tourist may find this to be of too little time and may need to use own judgement to adjust the time accordingly. 


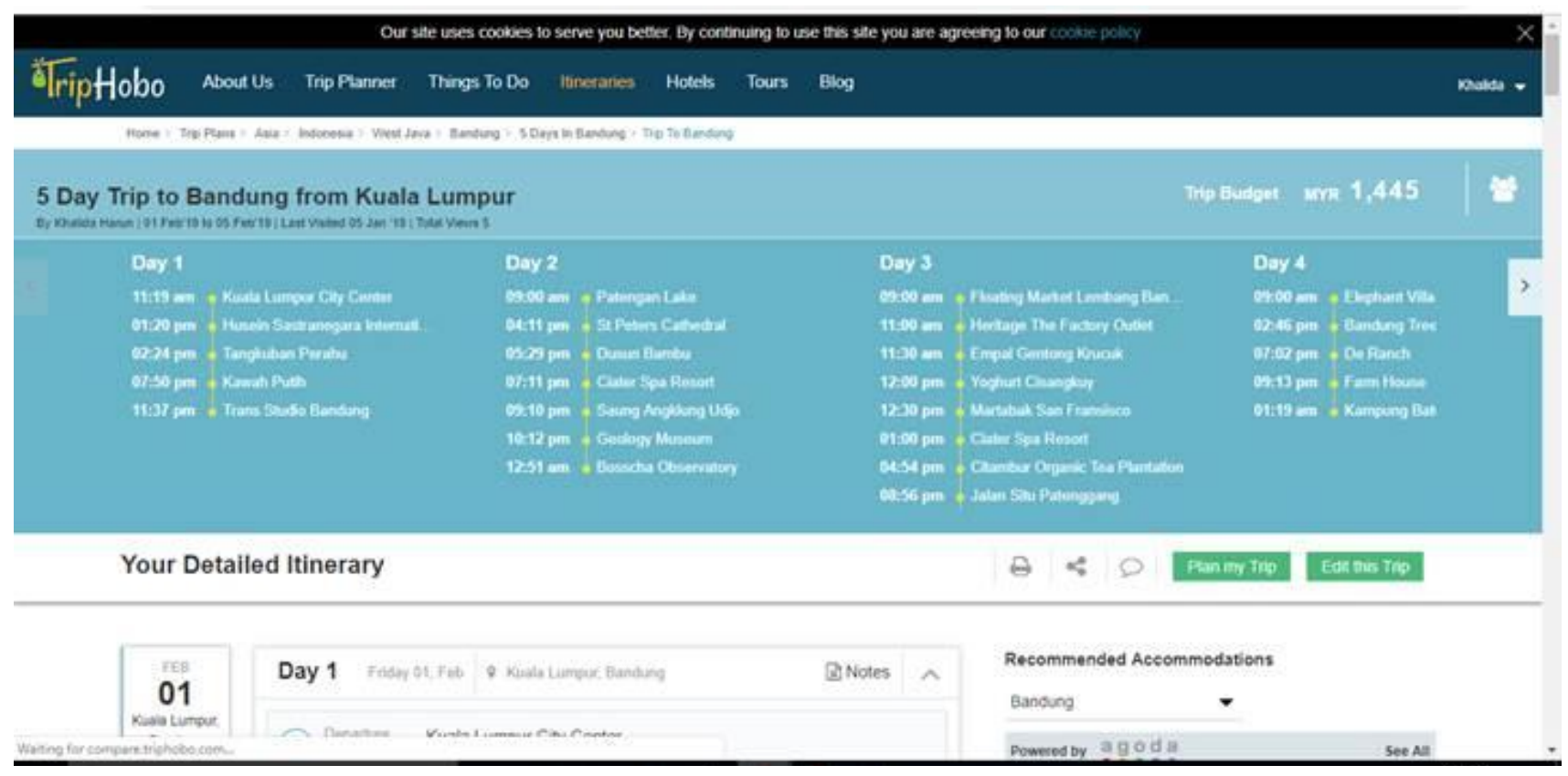

Figure 1. TripHobo user's detailed itineraries

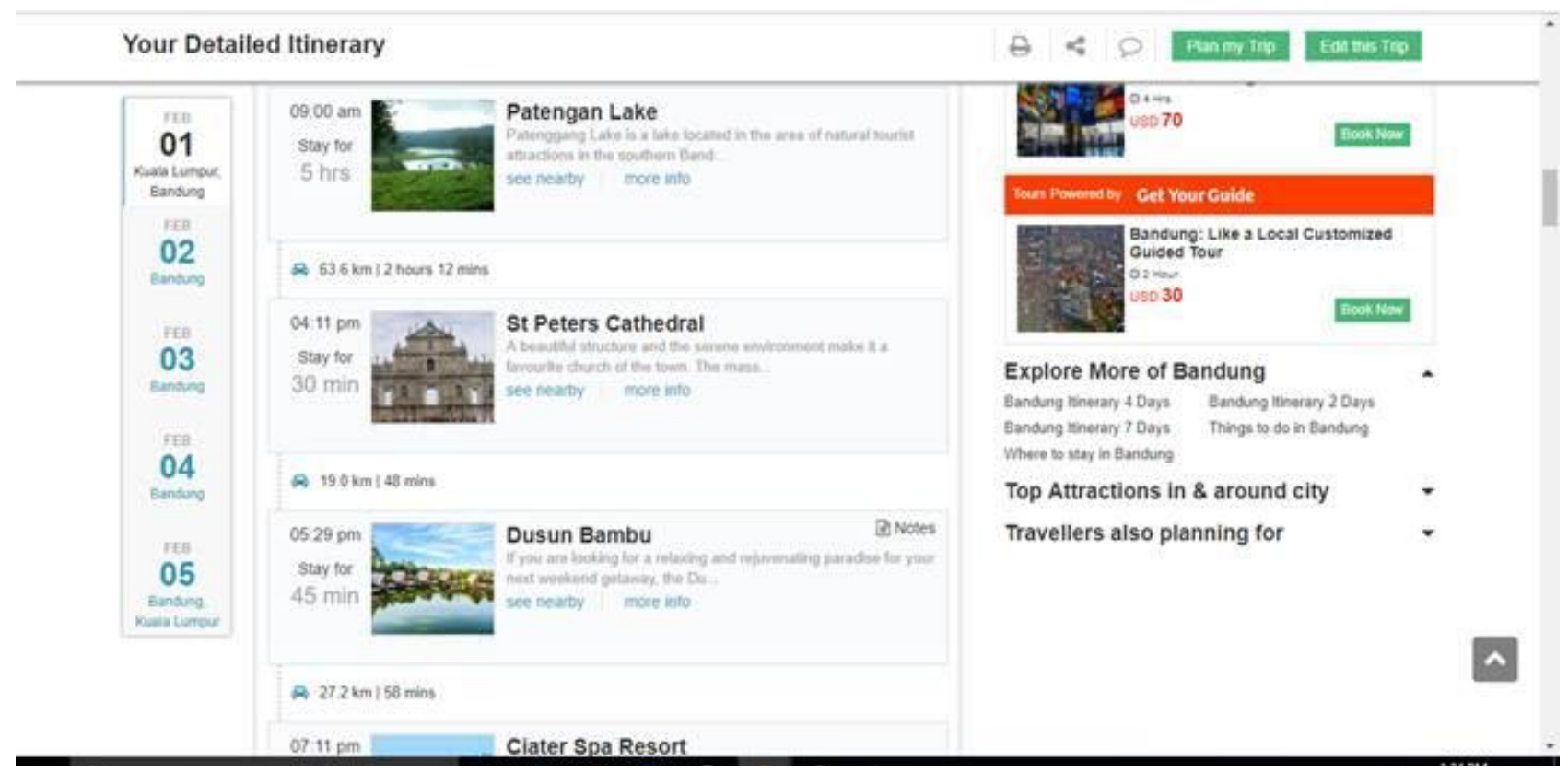

Figure 2. TripHobo itineraries with recommended timings 


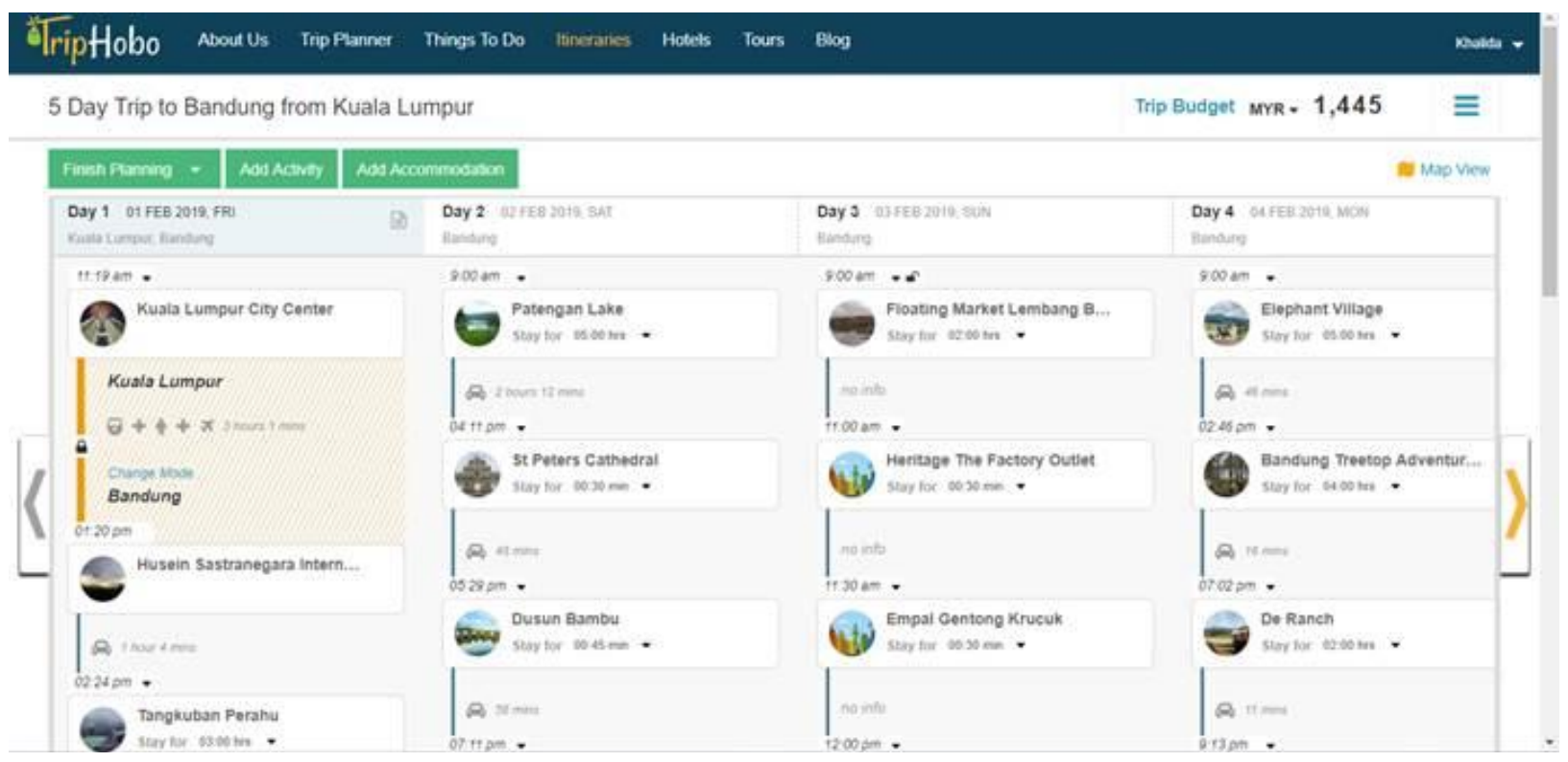

Figure 3. TripHobo summarised itineraries for all days

\subsection{Sygic}

Sygic Travel Map website application allows users to make itineraries for places, attractions, hotels, restaurants or shops directly onto the map. The strong feature is the Web Route Planner which allows users to generate a trip easily on the computer and then send it to the Sygic GPS Navigation app [11].

The GPS data is collected from connected personal navigation devices, commercial fleet GPS devices, mobile phone signals, road sensors, smartphones, and journalistic data and car dashboard systems. Furthermore, the website receives real-time traffic information, based on data from TomTom Traffic. The information, which is updated every 2 minutes is collected from more than 400 million drivers, therefore future travelers would have the most accurate and up-to-the-minute information [12].

The maps.sygic.com is filled with millions of Places (POIs) so that users can pick the places that they are keen to visit. The database consists of interactive virtual reality content with at least 5,000 unique $360^{\circ}$ travel videos and photos around the world. The website contains all the important details about opening hours, ticket prices, etc. [11].

The trip planning functions of the website allows users to customize their itineraries by registering as members, including via Facebook or Gmail. The interface is user friendly when it comes to adding trips to the selected days, and adding days and zooming into the map. The maps are in vibrant colours, pictured with brief information about places and the place icons on the map. While adding the itineraries to the day, the map would point to the location and provide a visual line linking it to the other new location(s) if those locations are also picked as shown in Figure 4 and Figure 5. Should the users pick several locations (which are available through several categories such as sightseeing, outdoor, restaurants, accommodation and many others), the website would auto arrange to optimize the route in that day. The route optimization however is not able to provide notification that the itineraries are almost full for the day and users could just go on to add more places. It also does not have any function to group nearby places into the same day of visit. Meaning it would optimize the route only within that day, not during the 5 days trip (For example if the user has selected a 5-day trip). Sygic is able to estimate the distance and travel time from one location to the other and indicate the opening and closing times for each place. However, the planning does estimate the time spent by the users at each place, which might not be ideal for all users. As shown in Figure 6, the route spans to more than 700km into another island and the tour expanded to more than 20 hours within a single day of visit. 


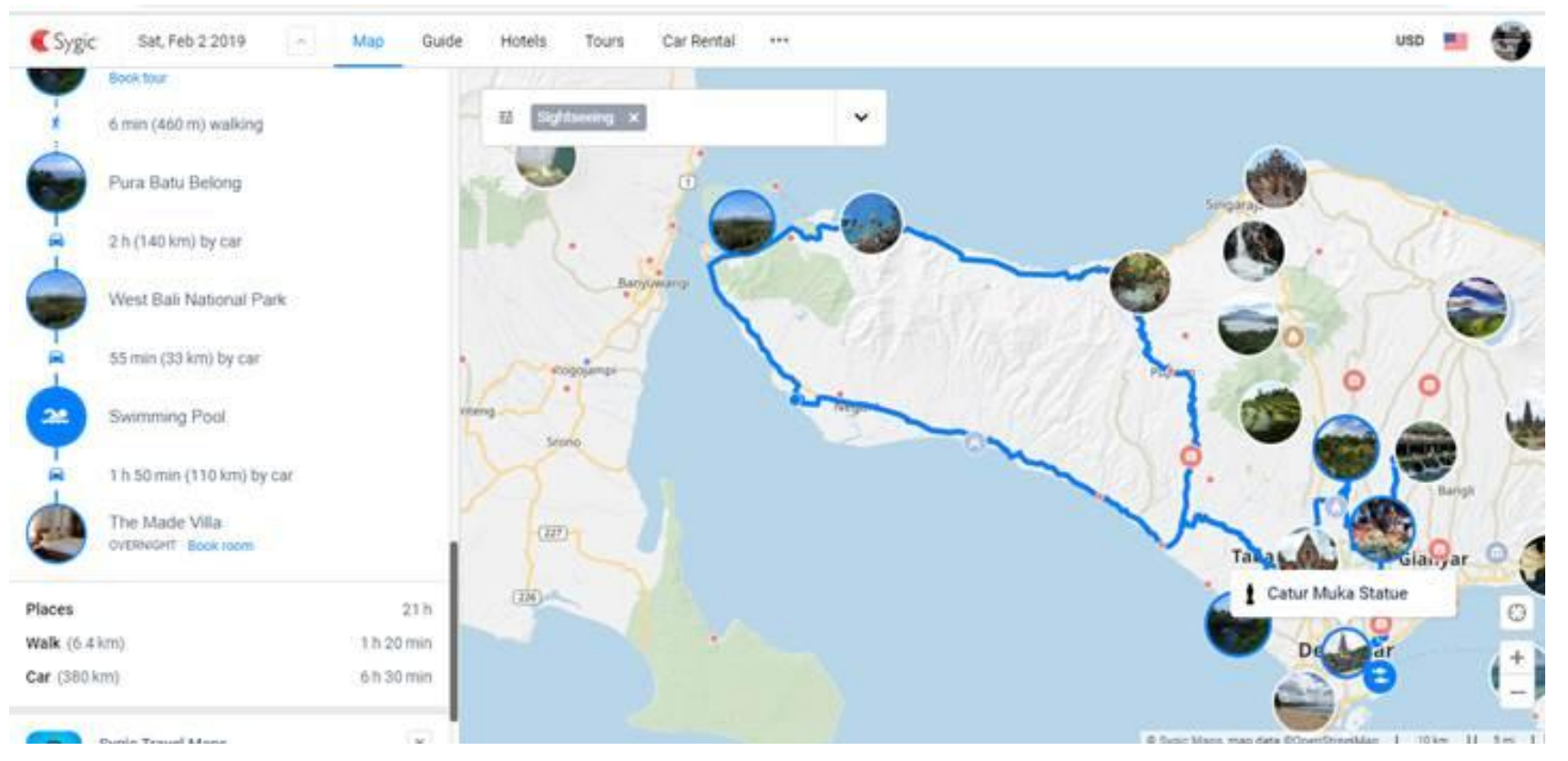

Figure 4. Sygic itineraries with suggested route according to GPS navigations

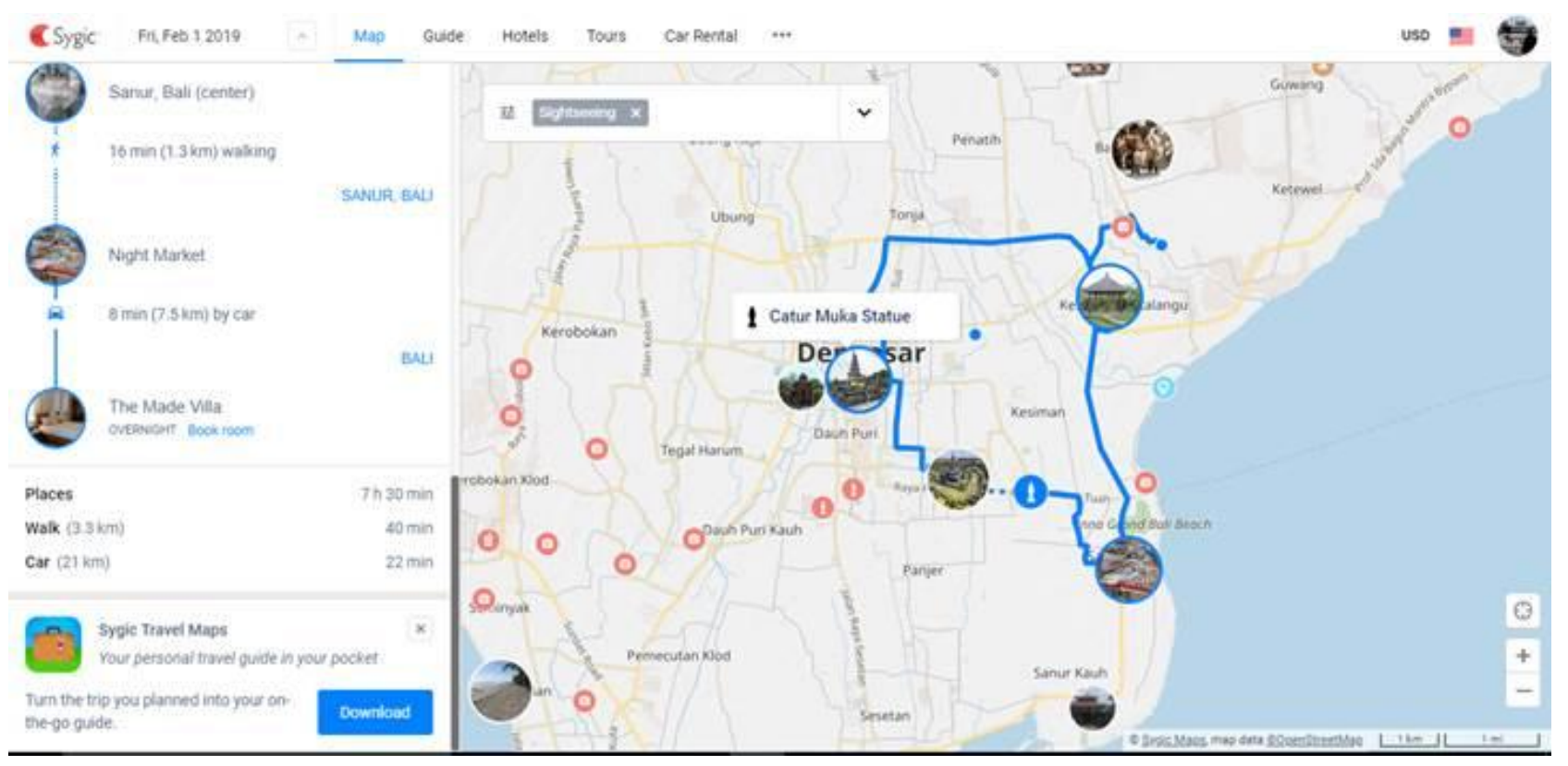

Figure 5. Sygic suggested route with time of journey 


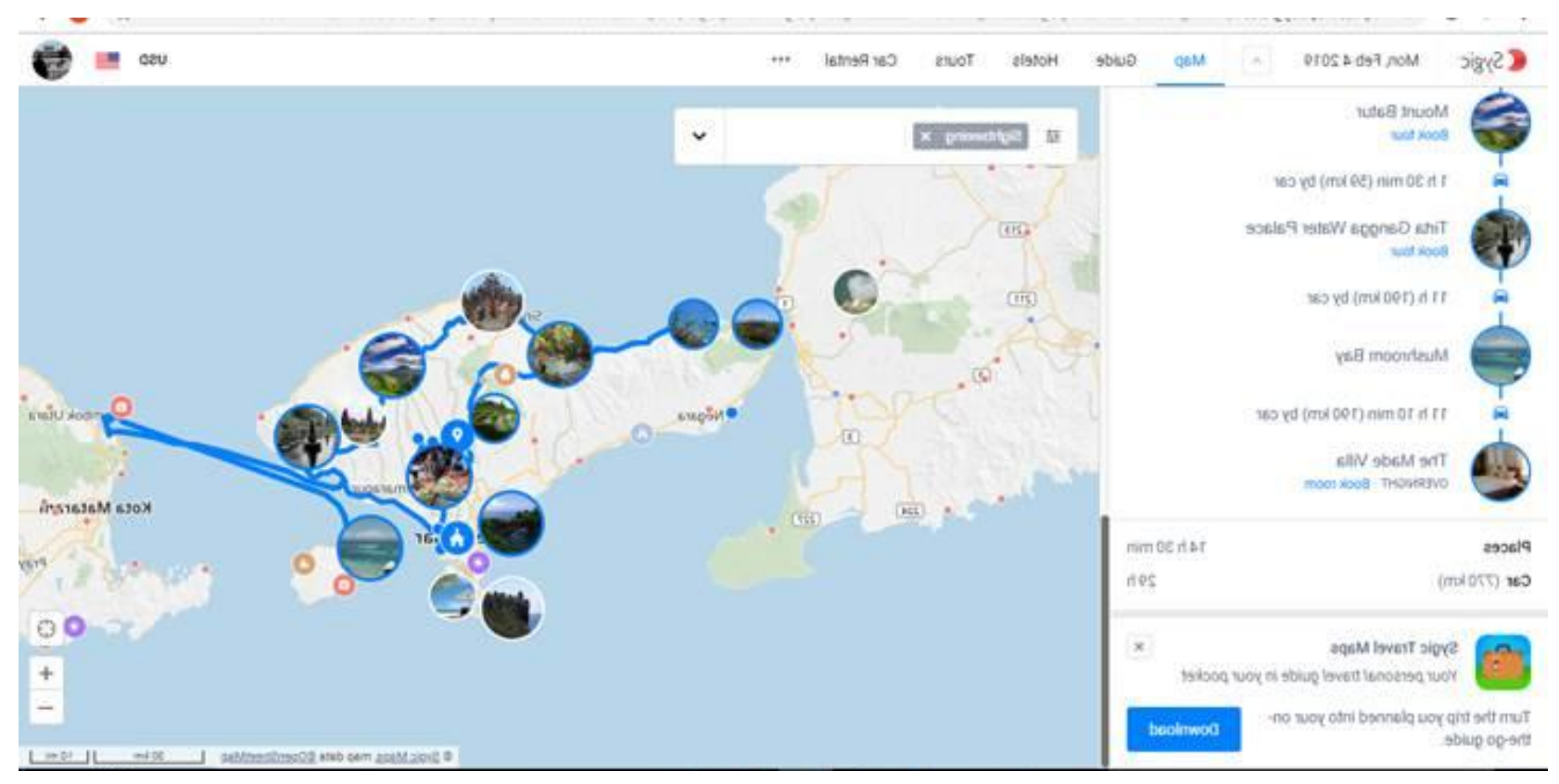

Figure 6. Sygic itineraries with no set time limit at locations

\subsection{Facebook}

According to Statista (2017), the world's most popular social network site ranked by the number of active users is Facebook with 2.05 billion active users [13]. As stated by Rahman (2017), Facebook is a social network that connects people with their friends and family or those who share common interests. Rahman (2017) further explained that Facebook Page is where Destination Marketing Organization (DMO) promotes destinations and attract more and more tourists by listing business details, recent events, locations in map, links to its official website, photos and video galleries [14]. Facebook is a place for tourists to get inspiration for a new trip. Besides DMO, when a normal user shares his/her experience at a travel destination, it helps to advertise the destination indirectly to the user's friends on Facebook.

The good thing of using Facebook in trip planning is that it allows users to create a group for discussion. The admin of the created group can add more people into the same group to discuss and plan a trip together. People in the group can share posts, links, images, files and many other things that might be useful for the trip planning. They can also discuss all the issues about the trip in the group such as transport, flights booking, accommodation booking, car rental and more. Besides, one of the group members may upload the itinerary that he/she had prepared and let other group members discuss about it. They may create a poll and let members vote for where to go and what to eat. In short, Facebook facilitates collaborative trip planning.

The limitation of Facebook is that it does not focus on the tourism domain [4]. Useful features for trip planning such as itinerary planner and booking features are not provided. It only makes the group trip discussions easier. 
Table 1(a) Comparison of Trip Applications (part 1)

\begin{tabular}{|c|c|c|c|}
\hline & TripAdvisor & TripHobo & Proposed system \\
\hline Main feature & $\begin{array}{l}\text { Largest travel review site } \\
\text { that facilitates decision } \\
\text { making process in trip } \\
\text { planning }\end{array}$ & $\begin{array}{l}\text { A website and mobile app } \\
\text { platform for user-generated } \\
\text { trip plans around the world. }\end{array}$ & $\begin{array}{l}\text { A web-bas ed application } \\
\text { which helps tourists to } \\
\text { search for attractions and } \\
\text { restaurants, construct } \\
\text { itinerary and facilitate group } \\
\text { trip discussions. }\end{array}$ \\
\hline Areas covered & Worldwide & Worldwide & Southeast Asia \\
\hline Search for & $\begin{array}{l}\text { Accommodations, } \\
\text { restaurants, attractions, } \\
\text { flights }\end{array}$ & $\begin{array}{l}\text { Accommodations, } \\
\text { restaurants, attractions, } \\
\text { flights }\end{array}$ & Restaurants, attractions \\
\hline $\begin{array}{l}\text { Filtering and } \\
\text { prioritizing } \\
\text { options }\end{array}$ & $\begin{array}{l}\text { Can filter based on } \\
\text { categories of } \\
\text { attraction/restaurants and } \\
\text { prioritize searchresult. }\end{array}$ & $\begin{array}{l}\text { Can filter based on } \\
\text { categories of } \\
\text { attraction/restaurants and } \\
\text { prioritize searchresult. }\end{array}$ & $\begin{array}{l}\text { Can filter based on } \\
\text { categories of } \\
\text { attraction/restaurants and } \\
\text { prioritize searchresult } \\
\text { according to ratings. }\end{array}$ \\
\hline $\begin{array}{l}\text { Review and } \\
\text { Rating }\end{array}$ & Yes & No & Yes \\
\hline $\begin{array}{l}\text { Create and } \\
\text { manage trip }\end{array}$ & $\begin{array}{l}\text { Yes, can create andmanage } \\
\text { multiple trips }\end{array}$ & $\begin{array}{l}\text { Yes, can create andmanage } \\
\text { multiple trips }\end{array}$ & $\begin{array}{l}\text { Yes, can create and manage } \\
\text { multiple trips }\end{array}$ \\
\hline $\begin{array}{l}\text { Itinerary } \\
\text { Planner }\end{array}$ & Yes & Yes & Yes \\
\hline $\begin{array}{l}\text { Auto-arrange } \\
\text { itinerary }\end{array}$ & No & No & Yes \\
\hline $\begin{array}{l}\text { Group trip } \\
\text { discussion }\end{array}$ & No & $\begin{array}{l}\text { No. Able to sharewith log- } \\
\text { in to Facebook, Twitter and } \\
\text { Googlet. }\end{array}$ & Yes \\
\hline Booking feature & $\begin{array}{l}\text { Partners with airlines, traval } \\
\text { agents and booking agents } \\
\text { to provide booking services. }\end{array}$ & $\begin{array}{l}\text { Partners with airlines, travel } \\
\text { agents and booking agents } \\
\text { to provide booking services. }\end{array}$ & No \\
\hline Map & $\begin{array}{l}\text { Static map is providedfor } \\
\text { each place to mark its } \\
\text { location. } \\
\text { Dynamic map is created by } \\
\text { users to mark the locations } \\
\text { of places they would like to } \\
\text { visit. }\end{array}$ & $\begin{array}{l}\text { Static map is provided for } \\
\text { each place to mark its } \\
\text { location. } \\
\text { Dynamic map is provided to } \\
\text { automatically mark the } \\
\text { locations of all chosen } \\
\text { attractions in a trip. }\end{array}$ & $\begin{array}{l}\text { Static map is provided for } \\
\text { each place to mark its } \\
\text { location. } \\
\text { Dynamic map is provided to } \\
\text { automatically mark the } \\
\text { locations of all chosen } \\
\text { attractions and restaurants in } \\
\text { a trip. }\end{array}$ \\
\hline
\end{tabular}


Table 1(b) Comparison of Trip Applications (part 2)

\begin{tabular}{|c|c|c|c|}
\hline & Sygic & Facebook & Proposed system \\
\hline Main feature & $\begin{array}{l}\text { A website and mobile app } \\
\text { platform demonstrate for } \\
\text { user-generated trip plans } \\
\text { around the world. }\end{array}$ & $\begin{array}{l}\text { Largest social network that } \\
\text { connects people with their } \\
\text { friends and people who } \\
\text { share the same interests. }\end{array}$ & $\begin{array}{l}\text { A web-based application } \\
\text { which helps tourists to } \\
\text { search for attractions and } \\
\text { restaurants, construct } \\
\text { itinerary and facilitate group } \\
\text { trip discussions. }\end{array}$ \\
\hline Areas covered & Worldwide & Worldwide & Southeast Asia \\
\hline Search for & $\begin{array}{l}\text { Accommodations, } \\
\text { restaurants, attractions, car } \\
\text { rentals }\end{array}$ & $\begin{array}{l}\text { Can search forpeople and } \\
\text { any topics including tourism }\end{array}$ & Restaurants, attractions \\
\hline $\begin{array}{l}\text { Filtering and } \\
\text { prioritizing } \\
\text { options }\end{array}$ & $\begin{array}{l}\text { Can filter based on } \\
\text { categories of } \\
\text { attraction/restaurants and } \\
\text { prioritize search result. }\end{array}$ & No & $\begin{array}{l}\text { Can filter based on } \\
\text { categories of } \\
\text { attraction/restaurants and } \\
\text { prioritize searchresult } \\
\text { according to ratings. }\end{array}$ \\
\hline $\begin{array}{l}\text { Review and } \\
\text { Rating }\end{array}$ & No & Uses comments and LIKEs & Yes \\
\hline $\begin{array}{l}\text { Create and } \\
\text { manage trip }\end{array}$ & $\begin{array}{l}\text { Yes, can create andmanage } \\
\text { multiple trips }\end{array}$ & $\begin{array}{l}\text { Can create group for trip } \\
\text { discus sion }\end{array}$ & $\begin{array}{l}\text { Yes, can create andmangeg } \\
\text { multiple trips }\end{array}$ \\
\hline $\begin{array}{l}\text { Itinerary } \\
\text { Planner }\end{array}$ & Yes & No & Yes \\
\hline $\begin{array}{l}\text { Auto-arrange } \\
\text { itinerary }\end{array}$ & No & No & Yes \\
\hline $\begin{array}{l}\text { Group trip } \\
\text { discussion }\end{array}$ & No & $\begin{array}{l}\text { Yes. Can create group for } \\
\text { trip discussion. }\end{array}$ & Yes \\
\hline Booking feature & $\begin{array}{l}\text { Partners with car rentals, } \\
\text { travel agents and booking } \\
\text { agents to provide booking } \\
\text { services. }\end{array}$ & No & No \\
\hline Map & $\begin{array}{l}\text { Dynamic map is created by } \\
\text { users to mark the locations } \\
\text { of places they wouldlike to } \\
\text { visit. }\end{array}$ & $\begin{array}{l}\text { Static map is provided for } \\
\text { each place to mark its } \\
\text { location. }\end{array}$ & $\begin{array}{l}\text { Static map is provided for } \\
\text { each place to mark its } \\
\text { location. } \\
\text { Dynamic map is provided to } \\
\text { automatically mark the } \\
\text { locations of all chosen } \\
\text { attractions and restaurants in } \\
\text { a trip. }\end{array}$ \\
\hline
\end{tabular}

\section{Survey on functional needs for trip advisory and planning system}

A survey has been conducted on random users in Malaysia. The survey is focused in the Kuala Lumpur area where the population is high and the potential for them to travel is also much higher compared to other states in Malaysia. In total there were 50 respondents who took part in the survey. $40 \%$ of them (20 persons) are from age range 18-26, 30\% (15 persons) are from age range 27-36 and the remaining 30\% (15 persons) are from age range 37-56. Among these 50 respondents, $52 \%$ (26 persons) are male and $48 \%$ (24 persons) are female.

As such, the survey had involved people from different age groups and gender. The number of respondents from different age group and gender is quite balanced. This is to avoid a biased result as people from different demographic groups may have different requirements, needs and expectations for the proposed system. 


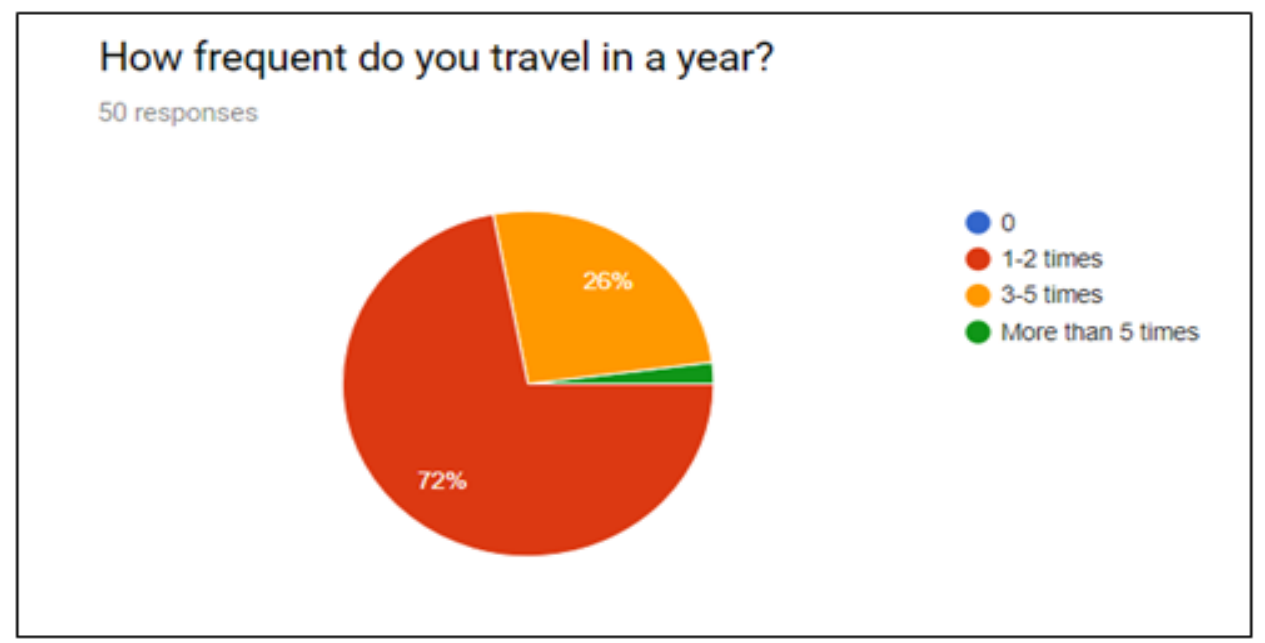

Figure 7. Travel frequency per year

As shown in figure 7, all 50 respondents travel at least once in a year. Out of 50 respondents, $72 \%$ of them travel 1-2 times in a year, 26\% of them travel 3-5 times in a year and 2\% of them travel more than 5 times in a year.

This shows that the responses provided by all respondents are applicable. Respondents should at least go for a trip once a year otherwise they may not have faced any problems in the trip planning process or see the need to have an application to solve the problems encountered.

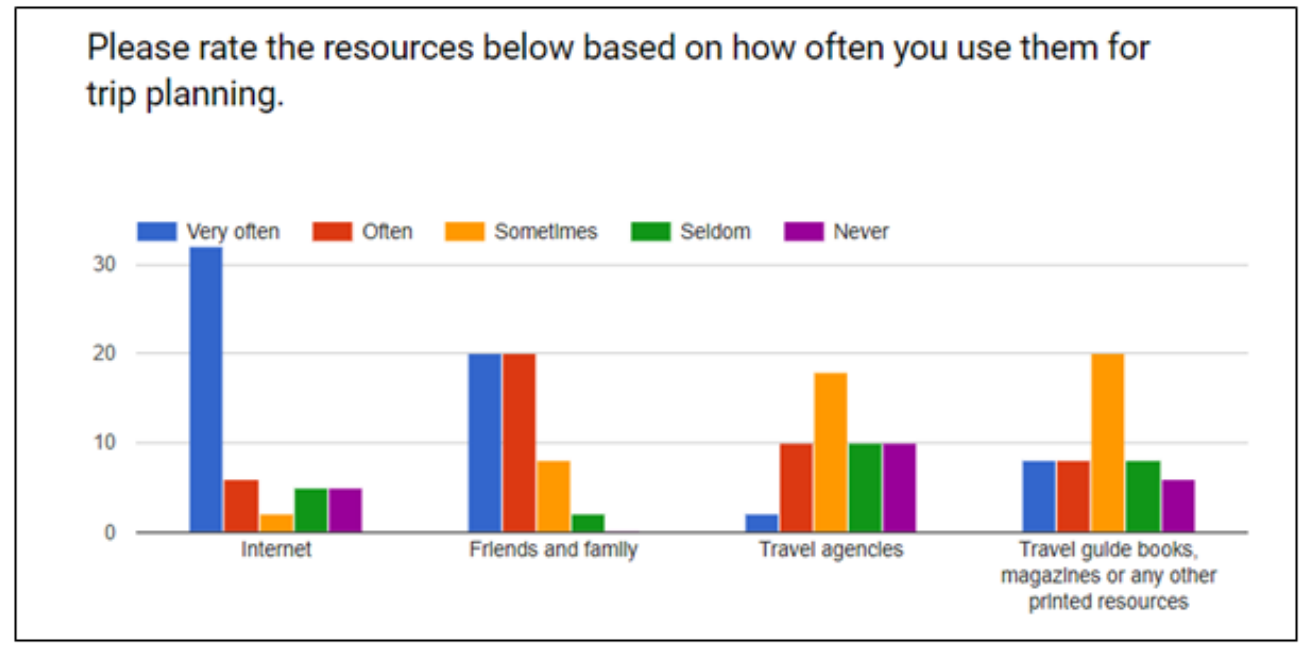

Figure 8. The use of resources for trip planning

As shown in the bar chart of figure 8, the most widely used resource for trip planning is Internet with more than half of the total respondents having used it very often, followed by friends and family. Travel guide books, magazines or any other printed resources are used even more frequently than travel agencies. The result shows that people nowadays tend to plan everything by themselves using different kinds of resources instead of using the services provided by travel agencies. They prefer to use Internet for trip planning as it is the most convenient, faster and cheaper way to access a vast pool of information and services. Besides, many respondents ask for help from friends and family for trip planning. There may be two probable explanations for this. First, their friends and family had visited the same travel destination before, so the respondents ask them for suggestions on places to visit and places to eat. Second, they are not involved in trip planning but may rely on their friends and family for planning the trip.

Based on the result, it shows that nowadays more and more people prefer to plan trip by themselves. The proposed system which intends to help people on planning trip is therefore feasible. 


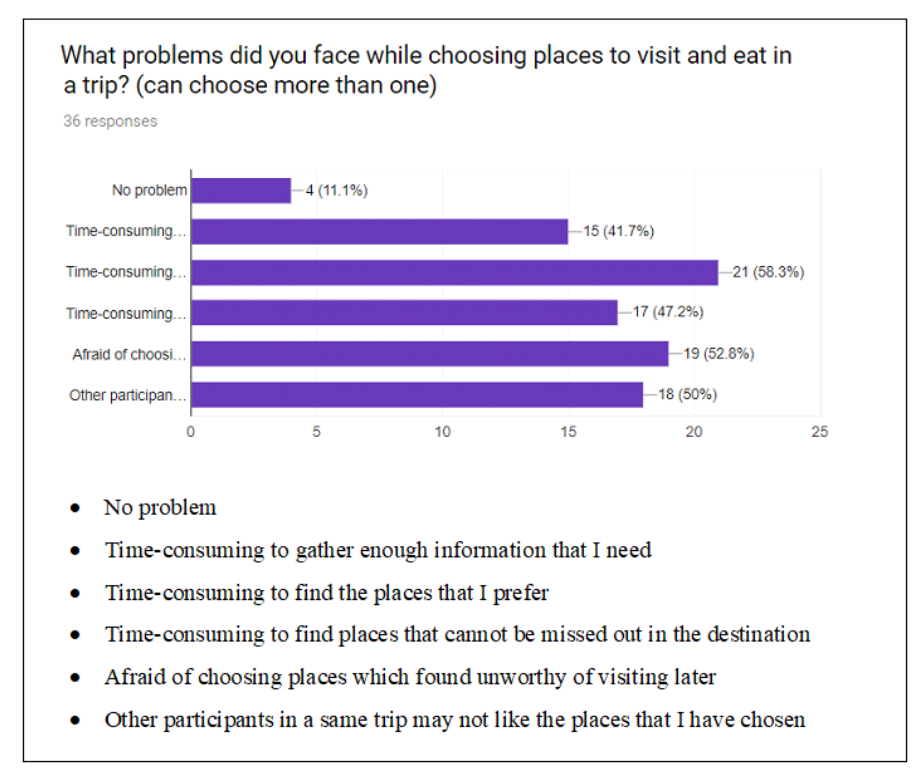

Figure 9. Problem faced during the trip

As shown in figure 9 , out of 50 respondents, $72 \%$ of them (36 persons) have planned a trip on their own before while the remaining $28 \%$ have not. Among those 36 respondents who had planned their own trips before, only 4 respondents think that they did not face any problems during trip planning while the remaining 32 respondents had faced different kinds of problem during trip planning.

Based on the result, the common problems faced by tourists while choosing places to visit and eat in a trip include time-consuming to find the places they prefer, time-consuming to find places that cannot be "missed out" at the destination, afraid of choosing places which were found unworthy of visiting later on in the trip and other participants in a same trip may not like the places that they have chosen to visit. To solve the first two problems, the proposed system should prioritize the list of attractions and restaurants based on ratings and filter the available options of attractions and restaurants based on tourists' preferences such as restaurants, shopping, sights \& landmarks, nature and more. To avoid choosing places that were found unworthy of visiting, the proposed system should let its users to read the reviews provided by peer users on the places they had planned to visit, so that they know what to be expected at those places. To prevent the last problem, the proposed system should let all the participants in a trip to view the itinerary of that trip and the information of every place in the itinerary at any given time and provide a discussion area for them to give their opinions.

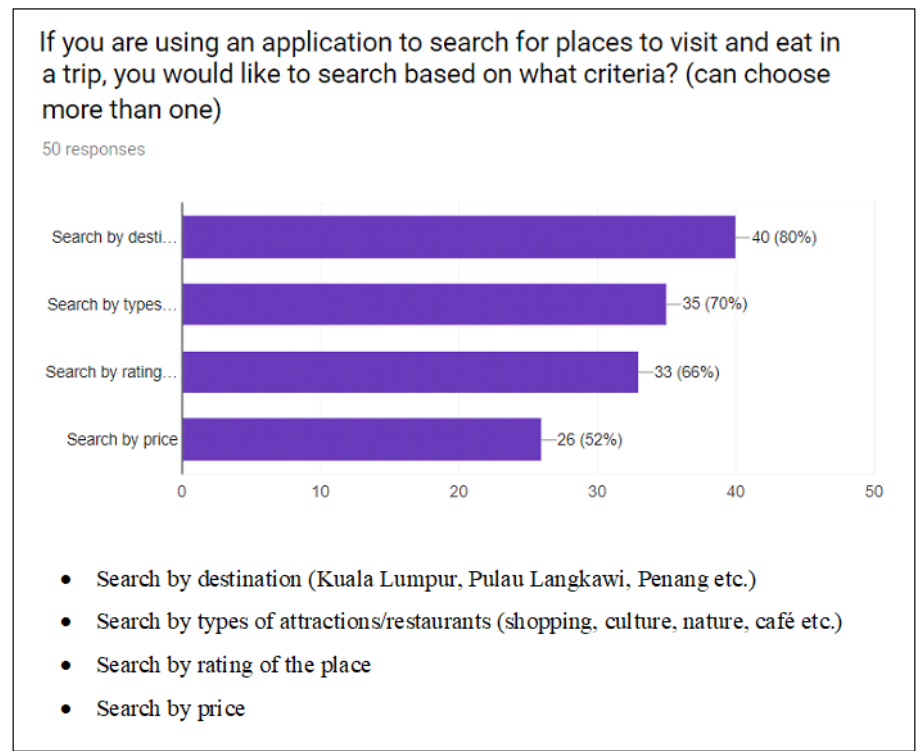

Figure 10. Preferable search criteria for trip application 
As shown in figure 10, it can be concluded that people would like to search by destination, types of attractions/restaurants and rating of the place when searching for places to visit and eat during a trip. The proposed system will also provide all these search criteria to help its users on finding their desired attractions and restaurants more effectively and efficiently.

\section{A Framework of Trip Advisory and Planning System}

This section will provide a detailed discussion on the process flow and the proposed framework for the trip advisory and planning system, which incorporates the k-means clustering algorithm.

\subsection{Sequence of Steps in the Auto Arrange Itinerary Function}

The trip organiser can choose to auto-arrange the itinerary for a trip. The system will assign places close to each other to the same day of visit to help travelers on reducing unnecessary transportation time and cost. This is done by using the k-means clustering algorithm. The k-means algorithm is used to group points similar with each other into a number of clusters, $\mathrm{k}$ specified by the trip organiser. In the case of the proposed system, $\mathrm{k}$ would be number of travelling days and points would be places of interest.

When the trip details page is first loaded, the system will retrieve the details of each chosen place such as place name, place photo and location from Google Places API by using the place Id stored in the database. While retrieving the details of each place, an array will be created to store the location of the place in the form of latitude and longitude. This array will then be added into another array to create the required clusters. When the request is complete, the system will display an alert to inform the user that the auto-arrange result is ready and asks the user to reload the page to get an updated itinerary, as shown in figure 11 below.

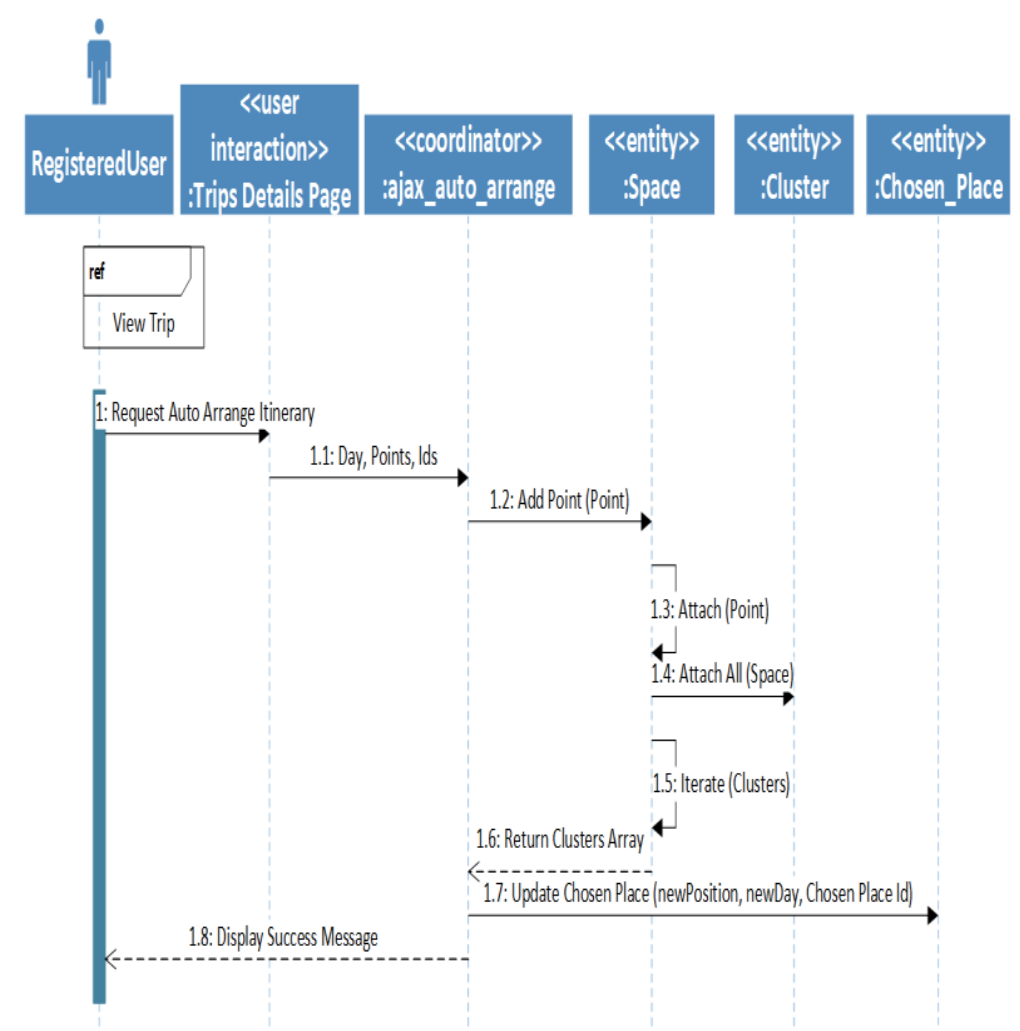

Figure 11. Sequence Diagram for Auto Arrange Itinerary Function 


\subsection{A Framework for Trip Advisory and Planning System using K-Means Algorithm}

Figure 12 shows the framework of the proposed system that divides the system into three components which are input, search processing and the output.

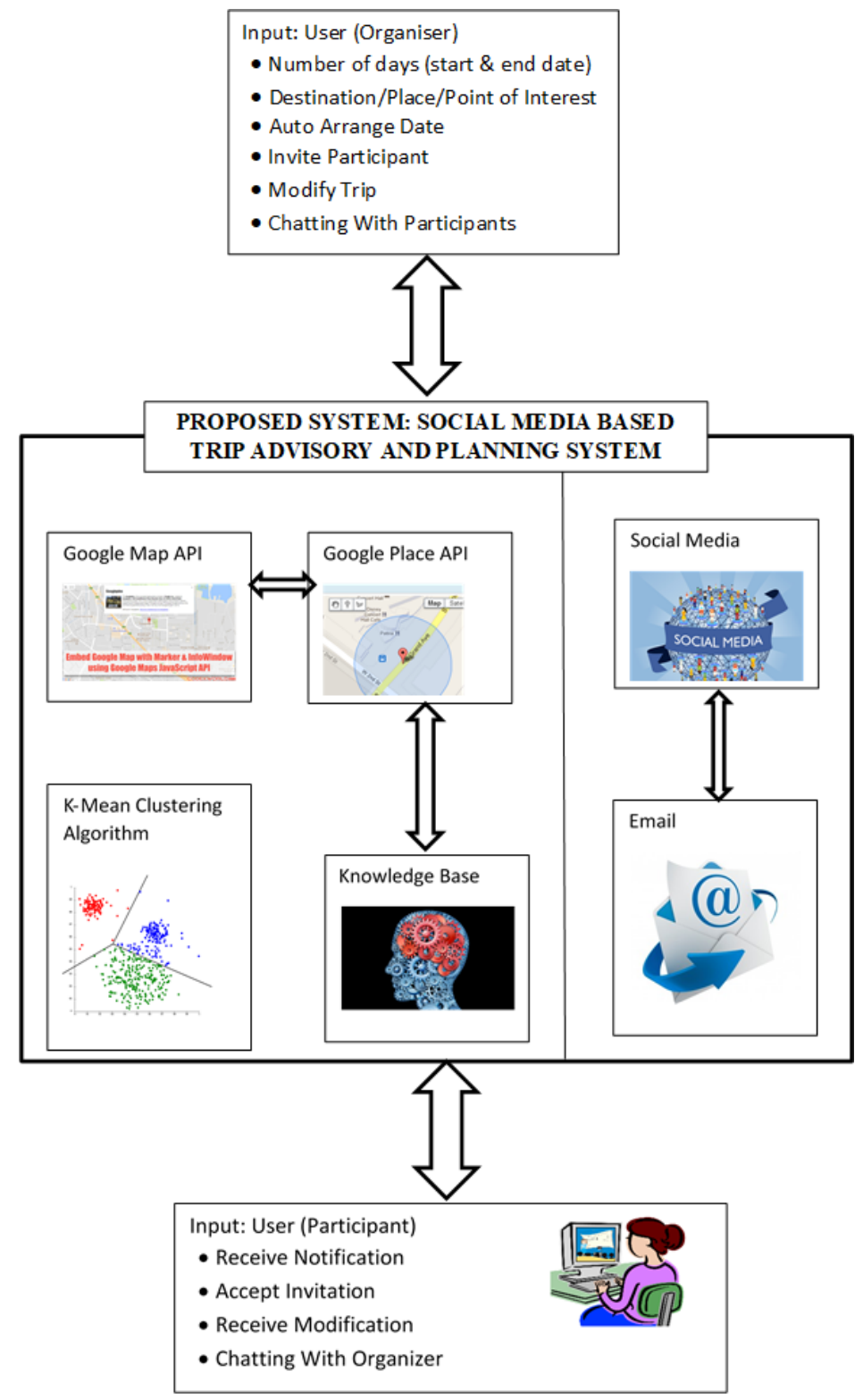

Figure 12. A Framework of the trip advisory and planning system incorporating the k-means algorithm

Based on figure 12, the input components need the users to give input on the start and end dates of the trip, destination details and points of interest which refers to the places to visit. Besides that the users are allowed to choose auto arrange date by the system, invite trip participants, modify trip details and chatting options to discuss trip details with all participants

\subsubsection{K-Means Clustering Algorithm}

The system also has an auto arrange itinerary feature which generates an itinerary for users based on the duration of their stay and the places they have chosen to visit. This is accomplished with the use of the kmeans clustering algorithm, which group places closest to each other by referring to their geographical locations found in the form of their respective longitudes and latitudes. 
Clustering is an unsupervised machine learning technique used to group data objects into clusters based on their similarity. These clustering algorithms can be broadly categorised as partition or hierarchical based, but other categories like density-based, grid-based, model-based and categorical data clustering algorithms have also emerged over the years with the advent of new data sets [15]. All partition based clustering algorithms aim to create clusters with low inter-cluster and high intra cluster object similarities. This is done with the use of some function, usually a distance matrix as in the case of the k-means algorithm.

According to $\mathrm{Wu}$ and Kumar [16], k-means is one of the most widely used algorithms in data mining and is relatively simple to implement and is fast when it comes to partitioning a data set into a number of clusters, $\mathrm{k}$, as specified by the user. K-means uses Euclidean distance to measure the distance between the data points in a data set. Euclidean distance is measured by calculating the straight-line distance between two points, as shown in the formula in figure 13 below.

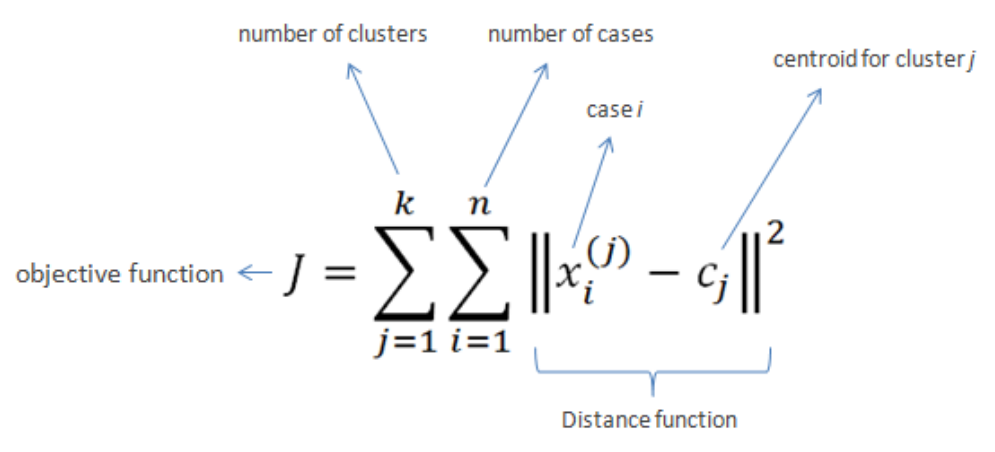

Figure 13. Euclidean distance function

The k-means algorithm intends to minimize the Euclidean distance between data points and their nearest cluster representative (centroid) and ensures that each data point belongs to exactly one cluster [16]. The steps in the k-means algorithm are as follows [17]:

1. Cluster the data points (i.e. the places to visit) into $k$ groups where $k$ is defined as the number of travel days.

2. Select $k$ data points at random as each cluster centre/centroid.

3. Assign data points to their closest cluster centre according to the Euclidean distance function.

4. Calculate the centroid or mean of all data points in each cluster.

5. Repeat steps 2,3 and 4 until the same points are assigned to each cluster in consecutive rounds.

The k-means algorithm however has some limitations. The first limitation lies in the number of clusters identified, $\mathrm{k}$ which must be specified in advance, but this requires prior knowledge of the given data set or trying with several different values to determine the optimal value of $\mathrm{k}$. The second problem is poor choices of initial centroids will cause the formation of poor clusters [16]. The third problem is that k-means is sensitive to outliers which will cause the centroids to be formed improperly [16].

As k-means is being used, the limitation of k-means algorithm should be eliminated or reduced to produce a result that is more accurate and satisfactory for the user. As mentioned above, the first problem of k-means is the value for $\mathrm{k}$, the number of clusters. In the case of the proposed system, $\mathrm{k}$ would be the number of travelling days, each day can be one cluster which have places (data points) close to each other so that travelers can visit them together to save on transport time and cost. The second problem is the poor choice of initial centroids as this will cause the clusters to be formed improperly. As the initial choice of centroids is done randomly, and since this is the nature of the algorithm, this problem is inevitable. The effect of this problem is reduced by running the algorithm repeatedly until each cluster is formed properly or it has exceeded the maximum number of tries set in the system. Rani, Nur Kholidah and Nurul Huda [18] have also made similar recommendations to run k-means several times with different initial centroids to produce the 
best clusters. In this system, if users are still not satisfied with the results, the system will suggest that the users try the auto-arrange feature for alternative results.

\subsubsection{APIs and Library use for the Proposed System}

One of the major functions of the proposed system is to let users to search for tourist attractions and restaurants within the Southeast Asia area and read their details. To achieve this purpose, the proposed will utilize Google Places API Web Service.

There are three services provided by Google Places API: Place Autocomplete, Place Search and Place Details. Place Autocomplete will predict places based on textual search strings and geographical bounds [19] (Google Developers, 2018). In the proposed system, users must specify the country to be visited and this will become the geographical bound. After that, users enter a state name or a city name and this will become the search string. Place Autocomplete services will then autocomplete the state/city name. The output of place autocomplete will be passed to Place Search service. The type of place search service to be used is text search service. This service will return a list of places based on the provided string [19]. The default string is "sights + landmarks+ in+ (output of Place Autocomplete)". Users can restrict the list to return places which match a specific place type such as shopping, museum, restaurants, outdoors and more.

The string will be altered and one more parameter (place type) will be passed to the request. Besides returning a list of places, the system would also embed a map to mark all the places in the place list. This can be done by using another API provided by Google, which is Google Maps JavaScript API. Lastly, Place Details can be used to retrieve information about a specific place [20]. After users choose one of the places in the search result list, the system will retrieve and display information of that place which includes contact number, website URL, address, opening hours, photos and reviews.

The main reason of choosing web services provided by Google is because Google is the largest and most widely-used search engine [21], hence the information provided by Google would be more complete and updated. Besides, the place information would be auto-updated by Google, and this can eliminate the need for a system administrator to manually update it from time to time.

For the library functions, PHPMailer library is chosen to send notification emails to all the participants in a trip when trip details such as name, start date and/or end date are modified by the trip organiser, or if a trip is cancelled by the organiser, new attractions or restaurants are added to or removed from the itinerary of the trip.

\section{Conclusions}

It is a fact that social media has great influence on tourists' decision-making process. The proposed system will thus utilize the power of word-of-mouth (reviews) to facilitate the decision-making process of tourists when choosing places to visit and eat during a trip. After comparing four different travel recommendation approaches that can be used to solve the information overload problem in the tourism industry, the proposed system will use knowledge-based recommendation to suggest a list of attractions and restaurants for users based on their specified needs (destination and type of attractions or restaurants). Lastly, after comparing four similar systems which include TripAdvisor, TripHobo, Sygic and Facebook as shown in Table 1(a) and Table 1(b), the proposed system aims to incorporate the good features of each system (reviews, itinerary planner and group trip discussion) and add some additional features to solve the problems identified in trip planning.

A web-based system is proposed to solve all the problems discussed. It can help tourists to search for attractions and restaurants faster as it lets users to filter available options according to their preferred categories. The system also prioritizes the result based on the ratings of these places. It is social media based which means that it lets the users to share reviews and opinions regarding the places they had visited with each other. This will aid tourists in decision making when deciding attractions and restaurants for a trip. This system will let users to create trip and invite participants to join the created trip. After users search and choose the attractions and restaurants for the created trip, the system will assist users in constructing the itinerary. Users can even choose to allow the system to auto-arrange the itinerary. The system will assign places close to each other to same day so they are visited together to save on unnecessary transportation cost and time. A map will be provided to mark the locations of all chosen places in the trip. This system also provides a discussion area for all the participants in a trip to discuss and plan their trip together. This system is ideal for a group of people who want to plan their trip by themselves. 


\subsection{Tangible Benefits}

- Reduced workload of tourists who plan trips by themselves. They do not have to record the attractions and restaurants for a trip manually and use a spreadsheet or document to draw the itinerary. They can use this system to search for the attractions and restaurants and add the ones they like directly into the itinerary which is provided upon the creation of the trip. Tourists also can choose to auto-arrange the itinerary based on the chosen places. The system will assign places close to each other in same day to ensure that they are visited together.

- Time-saving. Tourists can easily search for attractions and restaurants based on categories of places. The system will also prioritize the list of suggested places based on the ratings of those places.

- Cost-saving. Tourists can plan their trips by themselves and save on the commissions paid to travel agents.

\subsection{Intangible Benefits}

- Facilitating decision making. Tourists can read the reviews and ratings provided by other users for each place to know what is to be expected in each place.

- Easier planning. A map is provided to mark the locations of all chosen attractions and restaurants in a trip which help users to know the geographical distribution of all places chosen.

- Easier communication and sharing. All participants in a trip can view the itinerary and the information of every place in the itinerary by using the system at any time anywhere without the need for the trip organiser to manually share this information.

- Increased satisfaction for all trip participants. Participants in a trip can view the itinerary of that trip and be involved in the discussions and planning of that trip. Even if they do not want to be involved in the discussions, they would still know what has been decided and planned

\section{Acknowledgments}

The authors wish to express gratitude to the management of Asia Pacific University of Technology and Innovation (APU) for their support in this work.

\section{References}

[1] UNWTO and GTERC (2016). UNWTO/GTERC Annual Report on Asia Tourism Trends - 2016 Edition, Executive SummaryMadrid:UNWTO and GTERC.[online] Available at: http://www.eunwto.org/doi/pdf/10.18111/9789284418312 [Accessed 24 Aug. 2017]

[2] Januszewska, M., Jaremen, D. and Nawrocka, E. (2015). The effects of the use of ICT by tourism enterprises. Szczecin University Scientific Journal. Service Management, 16(883), p.65, [online]. Available at: http://www.wzieu.pl/zn/883/SM-16_ŻN-883_Januszewska_etAl.pdf [Äccessed 26 Jul. 2017].

[3] Moreno, A., Sebastia, L. and Vansteenwegen, P. (2015). Recommender Systems in Tourism. IEEE Intelligent Informatics Bulletin, $16(1)$, p.1., [online] Available at: http://www.comp.hkbu.edu.hk/ iib/2015/Dec/report/iib_vol16no1_report.pdf [Accessed 27 Jul. 2017].

[4] Luz, N. et al. (2013). Collective Intelligence in Toursplan An Online Tourism Social Network with Planning and Recommendation Services. In: Proceedings of the International $C^{*}$ Conference on Computer Science and Software Engineering. New York: Association for Computing Machinery
(ACM),[online]. https://www.researchgate.net/publication/262318593_Collective_intelligence_in_toursplan An_onlin e_tourism_social_network_with_planning_and_recommendation_services [Ācessed $26 \mathrm{Ju}$. 2017].

[5] Park, J. Y. \& Jang, S. C. (2013). Confused by too many choices? Choice overload in tourism. Tourism Management.,35 (April 2013) p.1-12. [Online]
http://www.sciencedirect.com.ezproxy.apiit.edu.my/science/article/pii/S0261517712000921

[Accessed 26 Jul. 2017].

[6] Awal, M. et al. (2016). A Hybrid Approach to Plan Itinerary for Tourists. In: IEEE 2016 5th International Conference on Informatics, Electronics and Vision (ICIEV 2016). New York: IEEE. [online] Available https://www.researchgate.net/publication/303402290_A_Hybrid_Approach_to_Plan_Itinerary_for_To urists [Accessed 30 Sep. 2017]. [7] Lim, K. H. (2016). Recommending and Planning Trip Itineraries for Individual Travellers and Groups
of Tourists. In: Proceedings of the 26th International Conference on Automated Planning and 
Scheduling (ICAPS'16, Australia: National ICT Australia. ), [Online] Available from: http://icaps16.icaps-conference.org/proceedings/dc/abstracts/lim.pdf [Ảccessed 26 Jul. 2017].

[8] Dareddy, M. (2016). Challenges in Recommender Systems for Tourism. In: the 10th ACM Conference on Recommender Systems (RecSys). New York: Association for Computing Machinery (ACM), [online]. Available at: http://ceur-ws.org/Vol-1685/paper11.pdf [Accessed 26 Ju1. 2017].

[9] MediaRoom (2017). Media Centre. [online] Available at: https://tripadvisor.mediaroom.com/myabout-us [Accessed 5 Sep. 2017].

[10] TripHobo.com (2019). About Us: TripHobo, [online]. Available at: https://www.tripobo.com/content/aboutus [Accessed: 12 Jan. 2019]

[11] Meri, A. (2018). Web Route Planner: Plan your routes in smarter ways, [online]. Sygic.com. Available at: https://www.sygic.com/blog/2018/web-route-planner-plan-your-routes-in-smarter-ways [Accessed: 12 Jan. 2019]

[12] Majchrakova, D (2016), Real-time Traffic Information - How Does It Work? [online]. Sygic.com.Available at: http://www.sygic.com/blog/2016/real-time-traffic-information-how-does-itwork [Accessed: 12 Jan. 2019]

[13] Statista (2017). Global social media ranking 2017 | Statistic. [online] Statista. Available at: https://www.statista.com/statistics/272014/global-social-networks-ranked-by-number-of-users/ [Accessed 1 Sep. 2017].

[14] Rahman, S. (2017). Tourism Destination Marketing Using Facebook As A Promotional Tool. IOSR Journal of Humanities and Social Science, [online] 22(2), pp.87-88. Available at: http://www.iosrjournals.org/iosr-jhss/papers/Vol.\%2022\%20Issue2/Version-1/M2202018790.pdf [Accessed 24 Aug. 2017].

[15] Nagpal, A., Jatain, A. \& Gaur, D. Review based on Data Clustering Algorithms, in Proceedings of 2013 IEEE International Conference on Information and Comminucation Technologies (ICT 2013), [online]. Available at: IEEE Xplore, http://www.ieee.org. [Accessed: 10 Jan. 2019]

[16] Wu, X. and Kumar, V. (eds.) (2009). The Top Ten Algorithms in Data Mining. Boca Raton, FL: CRC Press.

[17] Sayad, S. (2019). An Introduction to Data Science - K-Means Clustering, [online]. Saedsayad.com. Available at: https://www.saedsayad.com/clustering_kmeans.htm [Accessed: 11 Jan.2019]

[18] Rani, S., Nur Kholidah, K. \& Nurul Huda, S. (2018). A Development of Travel Itinerary Planning Application using Traveling Salesman Problem and K-Means Clustering Approach. 7th International Conference on Software and Computer Applications, 8-10 Feb. 2018, Kuantan, Malaysia [online]. Available at: https://doi.org/10.1145/3185089.3185142

[19] Google Developers (2018). Place Autocomplete | Google Places API Web Service | Google Developers. [online] Available at: https://developers.google.com/places/web-service/autocomplete
[Accessed 10 Feb. 2018].

[20] Google Developers (2018). Google Places API Web Service | Google Developers. [online] Available at: https://developers.google.com/places/web-service/ [Accessed 10 Feb. 2018].

[21] Alexa.com (2018). Alexa - Top Sites by Category: Computers/Internet/Searching/Search Engines. [online] Available
https://www.alexa.com/topsites/category/Computers/Internet/Searching/Search_Engines [Accessed 10 https://Www.
Feb. 2018]. 


\section{BIBLIOGRAPHY OF AUTHORS}

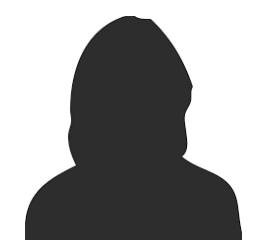

Lim Yen Yee is a former student at Asia Pacific University of Technology and Innovation (APU) Malaysia. She holds a Bachelor of Software Engineering degree with First Class Honours. She currently works in software development.

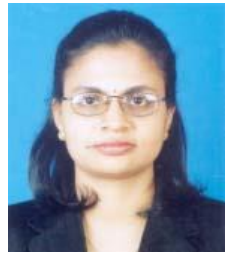

Seetha Letchumy M. Belaidan is a Lecturer at Asia Pacific University of Technology and Innovation (APU) Malaysia. She obtained her Master in Computer Science from USM. She is passionate about teaching and has over 20 years of teaching experience. Her research interests include database technologies, data analytics and visualization.

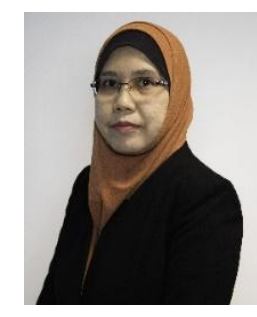

Nor Azlina Abd Rahman is a Senior Lecturer at Asia Pacific University of Technology and Innovation (APU) Malaysia. She obtained her Master in Computer Science from UiTM as the Dean's Merit award. She has been in the academic industry for 13 years and 10 years experienced working in industry as a System Analyst. Her research interest includes educational technology, cyber security, network security and other areas.

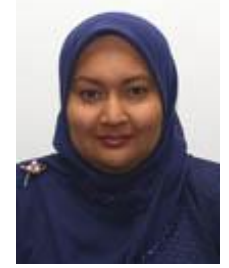

Khalida Shajaratuddur Harun is a Lecturer at Asia Pacific University of Technology and Innovation (APU) Malaysia. She obtained her Master in Information Technology With Distinction from University Malaya. She has been in the academic industry for 15 years and 9 years experienced working in industry as a Project Advisor. Her research interest includes educational technology, e-commerce, information system and other areas. 